\title{
A Study of the Electrochemistry of Polycrystalline Gold Electrodes in Aqueous Solution and Electrocatalysis by Large Amplitude Fourier Transformed Alternating Current Voltammetry
}

\author{
Benchaporn Lertanantawong ${ }^{1}$, Anthony P. O’Mullane ${ }^{2}$, \\ Werasak Surareungchai ${ }^{1}$, Mithran Somasundrum ${ }^{1}$, L. Declan Burke ${ }^{3}$ and Alan M. \\ Bond $^{2} *$ \\ ${ }^{1}$ School of Bioresources and Technology, King Mongkut's University of Technology \\ Thonburi, Thailand \\ ${ }^{2}$ School of Chemistry, Monash University, Clayton, Victoria 3800, Australia \\ ${ }^{3}$ Chemistry Department, University College Cork, Cork, Ireland
}

\section{Supporting Information}



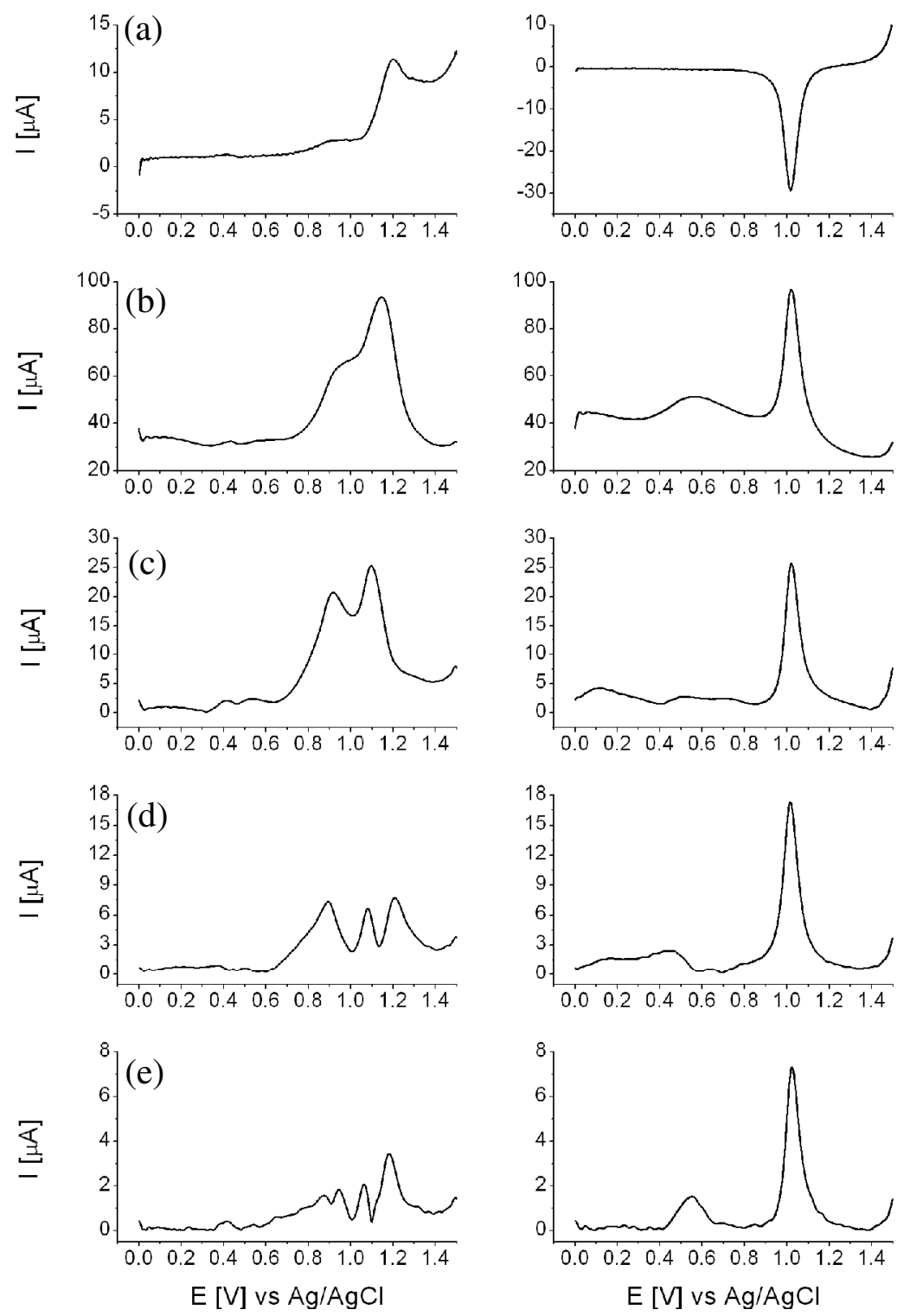

Figure S1: Large amplitude Fourier transformed ac cyclic voltammograms obtained for the dc (a) and fundamental to fourth harmonics (b-e) for an activated (mildly abraded) gold electrode in $0.5 \mathrm{M} \mathrm{H}_{2} \mathrm{SO}_{4}$. Conditions employed: $f=21.46 \mathrm{~Hz}, \Delta E=$ $150 \mathrm{mV}$ and $v=99.34 \mathrm{mV} \mathrm{s}^{-1}$. 